\title{
Chile y el Acceso a Información Pública. Comentarios sobre un Nuevo Fallo Adverso de la Corte Interamericana
}

Este comentario, junto a los

documentos que analiza,

está disponible en

www.anuariocdh.uchile.cl

Alex Muñoz Wilson*

\begin{abstract}
\#asta el momento son cuatro las sentencias de la Corte Interamericana de Derechos Humanos que han recaído sobre el Estado de Chile. Tres de ellas analizan el derecho a la libertad de expresión en alguna de sus dimensiones. El caso Claude et al. vs. Chile constituye la más reciente y será objeto de este comentario.

La expectativa era alta. Numerosas organizaciones de la sociedad civil -locales e internacionales-, académicos y otros actores interesados y vinculados con la protección del medio ambiente y la promoción de la transparencia, esperaban que la Corte se pronunciara por primera vez en un caso contencioso sobre la naturaleza y alcance del derecho al acceso a información pública. El fallo llegó el 19 de septiembre de 2006, ocho años después de interpuesta la correspondiente petición individual ante la Comisión Interamericana, y luego que el proyecto forestal que la motivó fuera suspendido hace otros tantos.
\end{abstract}

\section{Antecedentes del caso}

El caso versa sobre una solicitud de acceso a información pública, relativa a un proyecto de explotación forestal impulsado por una empresa extranjera en Chile. La preocupación principal de los solicitantes, futuros peticionarios, era el negativo impacto en el medio ambiente que dicho proyecto -conocido como "Río Cóndor" o "proyecto Trillium", en razón del nombre de la empresa inversionista- podía tener en una zona del extremo sur del país conocida por su rica biodiversidad y valioso bosque nativo. La información fue solicitada al Comité de Inversión Extranjera, único organismo autorizado por el Estado de Chile para aceptar el ingreso de capitales del exterior acogidos al Decreto Ley № 600 sobre inversión extranjera, y para establecer mediante los respectivos contratos entre el inversionista y el Estado la forma de materializar dicha inversión. La información requerida era de naturaleza comercial y permitiría a los solicitantes "evaluar los factores comerciales, económicos y sociales del proyecto [Río Cóndor], medir el impacto sobre el medio ambiente [...] y activar el control social respecto de la gestión de los órganos del Estado que tienen o han tenido injerencia en el desarrollo del proyecto de explotación..."1 . La solicitud fue respondida parcialmente, satisfaciendo cuatro de los siete puntos que la componían. Para obtener una respuesta completa, interpusieron ante los tribunales superiores de justicia chilenos un recurso de protección ${ }^{2}$, el cual fue declarado inadmisible de plano por "adolecer de manifiesta falta de fundamento".

* Abogado. Coordinador del Programa de Transparencia y Anti-Corrupción del Centro de Derechos Humanos, Facultad de Derecho, Universidad de Chile.

1 Párrafo 57 Sentencia. Cfr. comunicación de 7 de mayo de 1998 dirigida al Vicepresidente Ejecutivo del Comité de Inversiones Extranjeras por el Director Ejecutivo de la Fundación Terram (expediente de anexos a la demanda, anexo 1.1, folios 40 y 41); y declaración testimonial rendida por el señor Marcel Claude Reyes ante la Corte Interamericana durante la audiencia pública celebrada el 3 de abril de 2006.

2 Acción de naturaleza constitucional cuyo objeto es tutelar determinadas garantías constitucionales -entre ellas, la libertad de expresión- de la privación, perturbación o amenaza causada por acciones u omisiones ilegales o arbitrarias. 


\section{Comentarios sobre el fallo}

Lo que sigue a continuación estará centrado en los derechos consagrados en la Convención Americana sobre Derechos Humanos (CADH) respecto de los cuales la Corte se pronunció, ya sea estableciendo o desestimando la existencia de alguna violación. Veamos lo que dijo la Corte y sus implicancias.

\section{Artículo 13 (CADH)}

La sola emisión de este fallo constituye un importante paso en la generación de una esperada jurisprudencia sobre acceso a información pública como derecho humano. Sin embargo, su contenido no alcanza a reflejar el profundo desarrollo doctrinario que este derecho ha experimentado en círculos académicos y de organizaciones de la sociedad civil.

El grueso de la argumentación de la Corte se desarrolla en este capítulo sobre libertad de expresión. Es a través de ella -y sólo de ella- que la Corte justifica la existencia e importancia del acceso a la información como derecho. No quiero decir que esto sea incorrecto, sino simplemente hacer ver que no es la única vía jurídica para hacerlo. Tal como sostuvo que este derecho se entiende y se manifiesta como una dimensión de la libertad de expresión, la Corte también pudo haberlo configurado como un prerrequisito que hace posible el ejercicio de otros derechos como el derecho a la participación política del artículo 23. También están quienes se sienten más cómodos concibiendo el acceso a la información como un derecho autónomo e independiente, aunque debemos reconocer que el texto de la Convención Americana no da mucho espacio para esta postura, lo que obliga a una interpretación extensiva de alguno de los derechos ya incluidos en el catálogo. Todo esto revela la diversidad de opiniones sobre la materia.

En lo medular, la Corte reitera su doctrina explicitada desde la Opinión Consultiva OC-5/85 en adelante: "el artículo 13 de la Convención, al estipular expresamente los derechos a buscar y a recibir informaciones, protege el derecho que tiene toda persona a solicitar el acceso a la información bajo el control del Estado, con las salvedades permitidas bajo el régimen de restricciones de la Convención. Consecuentemente, dicho artículo ampara el derecho de las personas a recibir dicha información y la obligación positiva del Estado de suministrarla, de forma tal que la persona pueda tener acceso a conocer esa información o reciba una respuesta fundamentada cuando por algún motivo permitido por la Convención el Estado pueda limitar el acceso a la misma para el caso concreto" ${ }^{\prime \prime}$.

En varios párrafos de esta sección, el tribunal se ocupa de resaltar la importancia del derecho al acceso a información a través de múltiples citas a instrumentos internacionales distintos de aquellos propiamente de derechos humanos. Específicamente menciona normas de los ámbitos medioambiental y de lucha contra la corrupción. No queda claro, en todo caso, que dichas referencias busquen sólo demostrar el interés creciente del mundo contemporáneo en proteger este derecho o si, más bien, son traídas a colación por la Corte para enriquecer la interpretación del artículo 13 a la luz de los desarrollos producidos en otras ramas del derecho internacional.

A pesar de la indeterminación del motivo de estas citas, podemos sostener que, cualquiera sea el caso, la configuración del derecho en cuestión se ha beneficiado de los desarrollos producidos en otros ámbitos del derecho. Quizás en futuros fallos, la Corte podría insistir en esta vía haciendo explícita una interpretación extensiva de la Convención Americana, a partir de su artículo 29, letras (b) y (d). Podría argumentarse que dichas normas no se limitan sólo a los tratados de

\footnotetext{
3 Párr. $\mathrm{N}^{\circ} 77$.
} 
derechos humanos en sentido estricto sino que resultan aplicables también a otros instrumentos internacionales que, sin tener a los derechos humanos como su ámbito principal de aplicación, envuelven la regulación de alguno de ellos, estableciendo las obligaciones correlativas para el Estado. Así, por ejemplo, se incorporarían al ámbito de los derechos humanos los avances que ha experimentado el derecho internacional en materia de medio ambiente. De la misma forma, se profundizaría, a través de una interpretación sistemática del ordenamiento internacional, el tratamiento que la Convención Americana sobre Derechos Humanos brinda al derecho a la información, cuyo exiguo texto obliga a un mayor desarrollo dogmático.

Otro tanto ocurre con la mención a la Convención de Naciones Unidas contra la Corrupción, cuyas provisiones refuerzan las obligaciones del Estado respecto del derecho de acceso a información y su importancia para la rendición de cuentas y la fiscalización de los actos de la administración pública.

Ahora, ¿es el estatuto de la libertad de expresión exactamente igual al del derecho al acceso a la información pública? Creo que no. Al definir el alcance del derecho al acceso a información pública, la Corte omite algunas distinciones importantes. Si bien la libre difusión de ideas e información es una faceta de la libertad de expresión, el acceso a información pública implica obligaciones positivas distintas y mayores a las de garantizar el simple flujo de ellas. Al estar en juego el buen funcionamiento democrático, la fiscalización ciudadana, la toma de decisiones en asuntos de interés público, la transparencia, rendición de cuentas y responsabilidad de las autoridades públicas, entre otros fines de igual importancia, las obligaciones positivas del Estado van a más allá de crear las condiciones para garantizar el acceso a información e ideas cuando haya una solicitud de por medio. Estas imponen, además, la carga de publicar de propia iniciativa aquella información bajo control del Estado que sea útil y conducente a los fines señalados y, en algunos casos, incluso la obligación de procesarla y sistematizarla. En asuntos medioambientales, la necesidad de generar información amigable y de fácil acceso es aún más patente, toda vez que las evaluaciones de impacto ambiental de gran parte de los proyectos son de una alta complejidad técnica. Estos deberes de transparencia activa -propios del derecho al acceso a información pública-, si bien trascienden lo estrictamente relacionado con los hechos del caso, sí son relevantes para fijar los estándares que deben alcanzar los Estados para garantizar debidamente el derecho al acceso a información pública. En ese sentido, debieron haber sido abordados por la Corte.

Finalmente, la Corte valora los esfuerzos de Chile por adecuar su legislación a la Convención Americana sobre Derechos Humanos, a pesar de que los avances en el Estado chileno se han producido en el plano de la lucha contra la corrupción y en la transparencia de la gestión pública, pero no desde un enfoque de derechos.

\section{Artículo 8.1 y 25 (CADH)}

Esta es probablemente la parte más confusa de la sentencia. Primero, la Corte decidió que el Estado violó las normas del debido proceso (artículo 8.1) de dos de las tres víctimas en cuanto no recibieron respuesta por parte de un órgano administrativo -Comité de Inversión Extranjera- a su requerimiento de información. Luego, estimó que hubo violación de los artículos 8.1 y 25 (Protección Judicial), ahora respecto de los tres peticionarios, en razón de la denegación del recurso judicial que interpusieron luego de la negativa administrativa. En el primer caso, la tercera víctima fue excluida del amparo del artículo 8.1 porque sólo concurrió a la reclamación judicial pero no solicitó inicialmente la información al Comité de Inversión Extranjera.

Por un lado, resulta curioso que la Corte también haya declarado que esta víctima no vio vulnerado su derecho a la libertad de expresión, alegando la misma razón esgrimida para justificar su 
exclusión del artículo 8.1, es decir, por no haber suscrito la solicitud de información inicial. A mi juicio, este peticionario concurrió a interponer el recurso judicial para obtener una información determinada en poder de un órgano del Estado y, por lo tanto, la libertad de expresión en su dimensión de acceso a información fue igualmente violada. Al declarar inadmisible el recurso se le negó también el acceso al objeto a través del cual habría ejercido su libertad de expresión. No tiene sentido ejercer el derecho a un mecanismo judicial a través del recurso de protección sino es para solicitar a los tribunales la tutela de un derecho fundamental amparado por dicha acción constitucional. Por tanto, tal como se declaró violado su derecho a la protección judicial, también se debió haber estimado vulnerado su derecho contemplado en el artículo 13.

En cuanto a los alcances del artículo 8.1, coincido con el voto disidente ${ }^{4}$ en lo concerniente a las solicitudes administrativas. Para aplicar las normas del debido proceso debe existir, como es obvio, un proceso, es decir, un medio idóneo para resolver una controversia o conflicto de relevancia jurídica, situación que ocurre siempre que hay intereses contrapuestos entre partes. Esto no es propio de cualquier acto administrativo sino sólo de aquellos de naturaleza jurisdiccional, en los cuales se faculta al órgano administrativo para resolver tales controversias como tercero imparcial, adjudicando derechos a una u otra parte. La solicitud de acceso a información no constituye ni desencadena necesariamente un procedimiento jurisdiccional, como lo entiende el voto de mayoría. Para ello se requiere que haya un conflicto entre partes, como ocurre, por ejemplo, cuando se niega la información solicitada o cuando existe un tercero que se opone a su divulgación.

Ahora bien, respecto de la actuación judicial propiamente tal, sí deben aplicarse las normas del debido proceso. En la época de ocurrencia de los hechos, el recurso de protección era el mecanismo vigente para resolver sobre la titularidad del derecho y otorgar un remedio de carácter urgente frente a su vulneración.

Por su parte, en relación con el artículo 25, el problema es complejo puesto que existía un recurso disponible -el recurso de protección- pero no era eficaz, por cuanto los tribunales mantenían una jurisprudencia constante de restricción ilegítima a la libertad de expresión. Sin embargo, aún entonces, la regulación constitucional de este derecho, sumada a las normas contenidas en los tratados internacionales ratificados por Chile, posibilitaba que el recurso fuera acogido y garantizara el derecho de las víctimas. Desde esa perspectiva, el problema en este y en otros casos de vulneración de la libertad de expresión es más jurisprudencial que normativo. Sin perjuicio de que los Estados debieran contemplar una regulación y recursos específicos para amparar el acceso a información, es la falta de efectividad de normas ya vigentes la que origina las violaciones a esta dimensión de la libertad de expresión en Chile. Por lo tanto, este no fue precisamente un problema de regulación normativa sino de aplicación del derecho por parte de los tribunales de justicia chilenos. Esto se confirma al ver que, luego de promulgar una nueva legislación y crear un recurso judicial especial de amparo de acceso a información, los tribunales locales continúan rechazando dichos reclamos en la mayoría de los casos. En consecuencia, las medidas reparatorias debieron haberse dirigido a remediar la renuencia del Poder Judicial chileno a aplicar el derecho internacional de los derechos humanos.

\section{Artículo 23 (CADH)}

No cabe duda que el derecho a la participación política es distinto e independiente de la libertad de expresión y del acceso a información, cualquiera que sea el fundamento usado para explicar su naturaleza. Insólitamente, la Corte sólo destinó tres líneas para desestimar la violación al

4 El voto disidente corresponde a la Jueza Medina Quiroga y al Juez Abreu Burelli. 
artículo 23 señalando que "no [la] examinará [...] porque ya ha tomado en cuenta los argumentos formulados por el representante al respecto, al analizar la violación del artículo 13 de la Convención Americana". Esto resulta tan insuficiente como la "manifiesta falta de fundamento" invocada por los tribunales superiores chilenos.

Una vez fijado el marco fáctico del caso, la Corte tiene la obligación de calificar jurídicamente los hechos de manera de establecer las eventuales violaciones a la Convención Americana y determinar las responsabilidades que le correspondan al Estado al cual se le atribuyen. Por mucho que los argumentos esgrimidos sean similares a los ya planteados a propósito del artículo 13 -lo que no tiene nada de raro si se considera que ambos derechos están íntimamente ligados al funcionamiento de la democracia- no puede dejar de calificar los hechos y establecer las consecuencias jurídicas que de ellos derivan. La pasividad de la Corte respecto del artículo 23 no es consistente con lo afirmado por ella misma en el párrafo $N^{0} 111$ al tratar la violación al artículo 8. Respecto de este último "reitera su jurisprudencia sobre la posibilidad de que las presuntas víctimas o sus representantes invoquen derechos distintos de los comprendidos en la demanda de la Comisión" ${ }^{\prime \prime}$. El representante de las víctimas alegó que tanto el artículo 8 como el artículo 23 debían someterse al conocimiento de la Corte a pesar de no haber sido incorporados por la Comisión en su demanda. Sin embargo, la Corte hizo una diferencia inexplicable entre ambos al abordar sólo el primero.

Centrémonos en algunos hechos de la causa que son relevantes para estos efectos. Este proyecto implicaba la tala de aproximadamente 272.000 hectáreas de bosque nativo en la zona de Tierra del Fuego y contaba, además, con un importante y explícito respaldo político del Gobierno de la época. En cuanto a los peticionarios, uno de ellos era director de una ONG ambientalista; otro era director de una ONG que promueve estrategias jurídicas en casos de interés público, y el tercero era un diputado de la República, que por mandato constitucional debía fiscalizar los actos de la administración.

La naturaleza fáctica del asunto compromete el derecho a la participación política desde dos puntos de vista: (1) la evaluación de la ciudadanía sobre la política medioambiental del gobierno que podría incidir (o no) en su intención de voto en la elección de representantes (accountability vertical) y (2) las instancias formales de participación directa de la comunidad que la legislación chilena contempla para el sistema de evaluación de impacto ambiental, lo que incluye procesos de difusión de información, presentación de observaciones y posibilidad de interponer reclamaciones. De hecho, este proyecto pasó por esta calificación ambiental en dos oportunidades, no siendo aprobado en ninguna de ellas.

El acceso a información no sólo es un derecho en sí mismo sino que también hace posible el ejercicio de otros derechos, siendo la participación ciudadana evidentemente uno de ellos. Así lo ha hecho ver el Comité de Derechos Humanos de la ONU al señalar que "la libertad de expresión, la de reunión y la de asociación son condiciones esenciales para el ejercicio efectivo del derecho de voto y deben protegerse plenamente" . Asimismo, agrega que "los ciudadanos también participan en la dirección de los asuntos públicos ejerciendo influencia mediante el debate y el diálogo públicos con sus representantes y gracias a su capacidad para organizarse. Esta participación se respalda garantizando la libertad de expresión, reunión y asociación"7.

5 Cfr. Caso Acevedo Jaramillo y otros. Sentencia de 7 de febrero de 2006. Serie C No 144, párr. 280; Caso López Álvarez, supra nota 72, párr. 82; y Caso de la Masacre de Pueblo Bello. Sentencia de 31 de enero de 2006. Serie C No 140 , párr. 54.

6 Comité de Derechos Humanos. Observación General № 25, párr. 12.

7 Ibídem. Párr. 8. Ver, además, párr. 25. 
En el ámbito de la OEA se ha optado por promover la democracia representativa como forma de gobierno. Esto implica, entre otros rasgos característicos, la consagración del derecho de las personas a votar por sus representantes y a ser candidatas en elecciones democráticas. Es claro que la participación a través del voto necesita del acceso a información sobre las actuaciones relevantes, posturas ideológicas y méritos de los candidatos para poder optar entre uno y otro con conocimiento de causa. Sin esta precondición efectivamente garantizada, dicha dimensión de la participación política se ve perturbada y manipulada, dejando de ser libre y plena.

Por otra parte, la existencia de una democracia representativa no obsta a que se creen espacios de participación directa o, mejor dicho, derechos subjetivos de participación que requieren de condiciones básicas para ejercerse en plenitud. En este caso en particular, si bien los peticionarios no fueron privados completamente de su derecho a intervenir en los pocos espacios de control ciudadano existentes, sí debe concederse que su ejercicio se vio al menos entorpecido y, en todo caso, el juicio público sobre las consecuencias del proyecto se vio alterado en la medida que las personas no contaron con todas las vertientes de información necesarias para evaluar los hechos en toda su magnitud y definir su postura frente a ellos. El Estado debe garantizar las condiciones necesarias para el libre y pleno ejercicio de este derecho y, desde esa perspectiva, la participación ciudadana está condicionada directamente a la garantía del derecho a acceder a la información ambiental pertinente. La falta de información, su inexactitud o falsedad, distorsiona el juicio público sobre los hechos y perjudica el ejercicio de la participación de la cual es presupuesto fundamental. Constituir espacios formales de participación política sin información relevante sobre lo que se discute es, simplemente, una mera simulación.

Si se les negó la información a los peticionarios fue justamente para obstaculizar su acción e intervención en la formación de políticas públicas y en la evaluación de la gestión del gobierno en relación con el proyecto cuestionado.

Por lo tanto, si no se garantiza el acceso a dicha información se hace ilusorio el libre y pleno ejercicio de la participación política en un asunto público de naturaleza medioambiental, vulnerando de este modo el artículo 23.1. Habría sido conveniente que la Corte se pronunciara sobre la eventual violación al derecho a la participación política y que se refiriera a cómo se extiende, por un lado, al derecho a votar y ser votado en elecciones de representantes políticos -como es propio de una democracia representativa- pero, por otro lado, también a la posibilidad de intervenir y deliberar -directamente o representado- en asuntos de relevancia pública y en las instancias que corresponda. Desafortunadamente, se dejó pasar una buena oportunidad para que la Corte Interamericana desarrollara una jurisprudencia aún exigua en torno a este derecho.

\section{Reflexiones finales}

Como señalé en un principio, desde la denuncia de los peticionarios hasta el fallo de la Corte transcurrieron ocho años. El proyecto se encuentra cancelado hace mucho tiempo y la información solicitada carece hoy día de toda relevancia. Sin perjuicio de la importancia, en particular para las víctimas, de declarar la responsabilidad del Estado en la violación de los derechos humanos, es legítimo preguntarse qué sentido tiene un fallo que basa sus medidas de reparación en una situación ocurrida hace casi una década. Esto es particularmente discutible, sobre todo cuando Chile no sólo ha dictado nueva legislación sobre esta materia sino que, además, enfrenta actualmente un nuevo proceso de modificaciones, derogaciones y más reformas legales.

Sí hay que destacar que el fallo contribuye a señalar y reiterar que Chile tiene cuentas pendientes en materia de libertad de expresión en sus distintas dimensiones, así como en el ámbito de la participación ciudadana en los asuntos públicos y las condiciones que la hacen posible. Tomando 
esto en consideración, en lo que se refiere a reparaciones, la sentencia debió haber forzado al Estado a una adecuación del ordenamiento jurídico chileno a estándares internacionales sobre acceso a información. Ello habría requerido, en primer lugar, desarrollar esos estándares para que el Estado sepa qué debe cumplir y, en segundo lugar, decretar la adopción de medidas conducentes a que el Poder Judicial decida conforme a derecho aplicando las obligaciones internacionales de Chile en materia de derechos humanos.

Este caso tiene entre sus virtudes el unir el mundo de los derechos humanos con el medioambiental. Bien se sabe que este último descansa sobre la protección de tres derechos fundamentales: el derecho a la participación ciudadana en la toma de decisiones, el derecho a un remedio judicial o administrativo efectivo y, por cierto, el derecho a acceso a la información pública sobre cuestiones medioambientales. Una vez más se prueba la necesidad de armonizar las distintas ramas del derecho internacional y aprovechar la retroalimentación entre unas y otras para fortalecerse mutuamente. Ahí donde la protección de los derechos humanos es débil, también lo es la protección del medio ambiente.

Pero no sólo es necesaria la retroalimentación entre estos dos ámbitos sino también con las normas reguladoras del comercio internacional, frente a las cuales usualmente se producen tensiones, generando los peores costos de la globalización. Los problemas derivados de las estrategias de desarrollo de los países no son unidimensionales sino que abarcan varios campos de interés en forma simultánea. Conceptos como el de desarrollo sustentable han servido para compatibilizar el crecimiento económico con la protección del medio ambiente, el cual, en los últimos años, también ha reconocido e incorporado una dimensión social a través de la protección de los derechos fundamentales. Estos tres ámbitos están íntimamente ligados entre sí y todos imponen obligaciones igualmente vinculantes a los Estados, a veces en forma contradictoria. Le cabe un importante rol a las organizaciones internacionales, políticas y jurisdiccionales, en cuanto a interpretar dichas obligaciones de manera compatible, siempre procurando avanzar en la protección de las personas y el mejoramiento de sus condiciones de vida.

Para terminar, una nota curiosa y optimista. Luego de que la empresa sucesora de Trillium quebrara, el Banco acreedor decidió donar la totalidad de los terrenos para que fueran convertidos en un santuario de la naturaleza, impidiendo su depredación y posibilitando su conservación para las generaciones futuras. 